\title{
ANÁLISIS
}

\section{PUC: PRÉSTAMO CONSORCIADO DE LAS BIBLIOTECAS DEL CBUC}

\author{
Marta Tort, Lluís Anglada, Elisabet Cassà, Jordi Pallarès y Ramon Ros
}

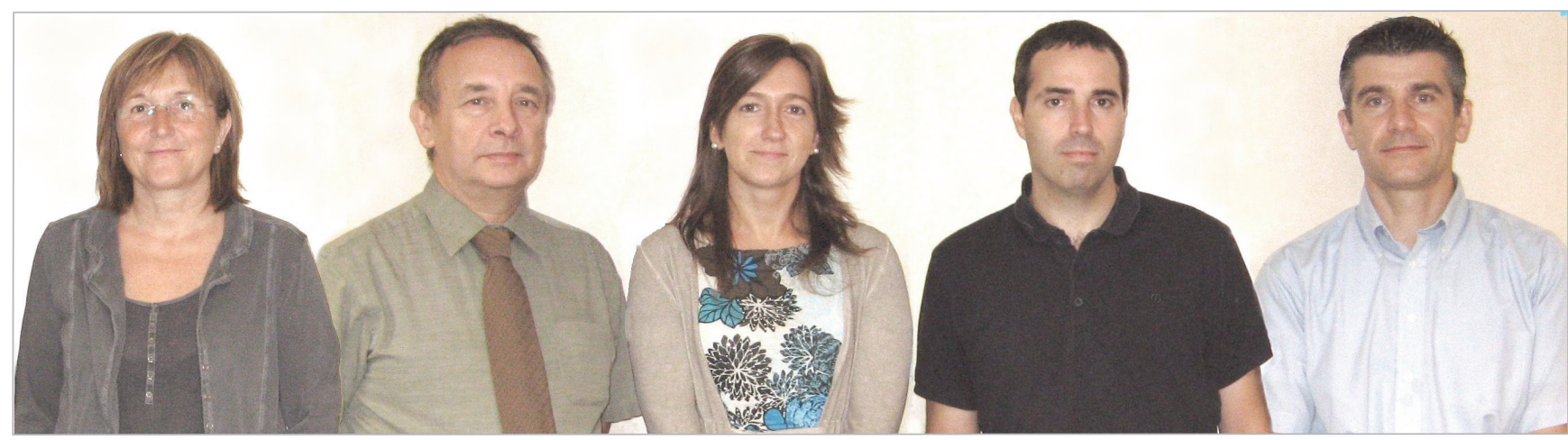

Marta Tort es responsable del soporte bibliotecario del Consorci de Biblioteques Universitàries de Catalunya desde 1996 con especial dedicación a la gestión del Catàleg Col-lectiu de les Universitats de Catalunya (CCUC) y al servicio de préstamo consorciado. Anteriormente fue jefe de la sección de proceso técnico del Servei de Biblioteques de la Universitat Autònoma de Barcelona y bibliotecaria del Institut Català de Bibliografia de la Generalitat de Catalunya. Es diplomada en biblioteconomía y documentación.

http://orcid.org/0000-0001-5174-8068

mtort@cbuc.cat

Lluís Anglada es director del Consorci de Biblioteques Universitàries de Catalunya (CBUC) desde 1997. Anteriormente fue director de las bibliotecas de la Universitat Politècnica de Catalunya y profesor de la Escola Universitària Jordi Rubió i Balaguer de Biblioteconomia i Documentació de Barcelona. Es licenciado en filosofía y diplomado en biblioteconomía y documentación. Ha sido miembro del Global Council de OCLC y actualmente pertenece a la Comisión Ejecutiva de Liber. Es autor y promotor de los blogs Bdig y Blok de Bid. Imparte regularmente talleres y conferencias y publica artículos sobre bibliotecas y consorcios bibliotecarios.

http://orcid.org/0000-0002-6384-4927

langlada@cbuc.cat

Elisabet Cassà es master en gestión de contenidos digitales, licenciada en documentación y diplomada en biblioteconomía y documentación por la Universitat de Barcelona. Trabaja en el Consorci de Biblioteques Universitàries de Catalunya desde 2004, donde ejerce diversas funciones de soporte técnico y coordinación en el ámbito del catálogo colectivo y del préstamo interbibliotecario. Desde 2009 se dedica a la consultoría virtual en el Col·legi Oficial de Bibliotecaris Documentalistes de Catalunya.

http://orcid.org/0000-0003-3950-7581

ecassa@cbuc.cat

Jordi Pallarès es ingeniero técnico en informática de sistemas por la Universitat de Lleida. Trabaja en el Consorci de Biblioteques Universitàries de Catalunya desde 2001 como responsable informático del catálogo colectivo, el PUC y el clúster.

https://orcid.org/0000-0001-9379-2366

jpallares@cbuc.cat

Ramon Ros, licenciado en informática por la UPC y posgrado en dirección de departamentos de informática, ha trabajado en la Universitat de Barcelona en el departamento de comunicaciones, y en la Universitat de Lleida donde puso en marcha la automatización de la biblioteca. Desde 1998 es jefe de informática del Consorci de Biblioteques Universitàries de Catalunya. Entre otros, ha sido miembro de grupos de trabajo para el estudio, evaluación e implantación de los nuevos sistemas de gestión de las bibliotecas del CBUC y de sus repositorios.

http://orcid.org/0000-0003-3809-9547 


\title{
Resumen
}

Se describe brevemente el estado de la cuestión sobre el préstamo interbibliotecario (PI) consorciado a nivel internacional, y se explican las limitaciones del anterior servicio de PI del Consorci de Biblioteques Universitàries de Catalunya (CBUC) y su evolución hacia el nuevo servicio de préstamo de libros, el PUC, que se ha implementado recientemente. Se detalla la selección del software, el reglamento, la logística del PUC y su funcionamiento técnico. Se destacan las mejoras que ha supuesto el PUC como la de ser un servicio iniciado por el propio usuario, que puede pedir el libro a través del Catàleg Col/lectiu de les Universitats de Catalunya (CCUC) directamente a la biblioteca que lo tiene, sin mediación del personal de biblioteca y la reducción del tiempo de espera y de costes que esto supone.

\section{Palabras clave}

Préstamo interbibliotecario, Préstamo consorciado, Préstamo iniciado por el usuario, PUC, Obtención de documentos, Consorci de Biblioteques Universitàries de Catalunya, Catàleg Col/lectiu de les Universitats de Catalunya, Bibliotecas universitarias, España, Cataluña.

\section{Title: PUC: lending service of the CBUC libraries}

\begin{abstract}
A brief description of the international state of interlibrary loan (ILL) is presented. The limitations of the previous ILL service provided by the Consortium of University Libraries in Catalonia (CBUC) and its evolution to the new consortial borrowing service, the PUC, are described. The software selection, rules, logistics, and how the system works are detailed. The improvements the PUC represents as a patron-initiated service where the user can place a book request through the union catalog (CCUC) directly to the library that owns it, without mediation by library staff, have reduced waiting time and costs.
\end{abstract}

\section{Keywords}

Interlibrary loans, ILL, Patron-initiated borrowing, Consorci de Biblioteques Universitàries de Catalunya, Catàleg Col·lectiu de les Universitats de Catalunya, University libraries, PUC, Document delivery, Spain, Catalonia.

Tort, Marta; Anglada, Lluís; Cassà, Elisabet; Pallarès, Jordi; Ros, Ramon. "PUC: préstamo consorciado de las bibliotecas del CBUC". El profesional de la información, 2012, noviembre-diciembre, v. 21, n. 6, pp. 613-620.

\section{Introducción}

El préstamo entre bibliotecas es una de las actividades cooperativas más antiguas de las bibliotecas ya que debemos recordar que los centros monásticos se intercambiaban libros para poderlos copiar e incorporarlos a sus bibliotecas. Evidentemente el servicio ha evolucionado mucho desde entonces y su vigor puede verse reflejado en las ochenta revisiones de bibliografía sobre el tema publicadas hasta ahora por la revista Interlending \& document supply ${ }^{1}$ o en el $660 \%$ de incremento del servicio experimentado por las bibliotecas de la Association of Research Libraries (ARL) entre 1974 y 2008 (Mak, 2011, p. 26).

A pesar de ser un servicio bibliotecario de muy larga tradición, el préstamo interbibliotecario (PI) experimentó un gran empuje en las décadas de los años 70 y 80, cuando la informática empezó a aplicarse a las bibliotecas. Los costes de los ordenadores obligaron a las bibliotecas a compartirlos, y esos usos compartidos generaron redes y cooperativas de bibliotecas que crearon catálogos colectivos a partir de los que se establecieron los modernos servicios de préstamo interbibliotecario. Como ha sido una constante en las bibliotecas, al PI se le fueron aplicando tecnologías modernas a medida que iban surgiendo. Así, para hacer las peticiones de documentos se usó el télex además del correo postal, o, más tarde y también para el suministro, el fax y la transmisión electrónica de ficheros.

\section{Los usuarios valoran mucho poder con-} seguir un documento que no forma parte de la colección de su biblioteca

El PI se ha ido estabilizando y, a pesar de no estar ahora entre los servicios bibliotecarios que generan más usos, produce unas cifras de movimiento que, a nivel de sistema regional o nacional son notables, como los 456.000 préstamos interbibliotecarios anuales en el consorcio Orbis Cascade, los 189.000 en el consorcio Mobius o los 850.000 del Ohiolink, los tres en los Estados Unidos de Norte América. Sin embargo, aunque el PI sea cuantitativamente menor que otros servicios, su impacto cualitativo es muy alto, ya que los usuarios valoran mucho poder conseguir un documento que no forma parte de la colección de su biblioteca.

En 1994 el consorcio OhioLINK fue el primero en ofrecer el préstamo interbibliotecario bajo una modalidad innovadora (Munson, 2006). La existencia de un catálogo colectivo y el 


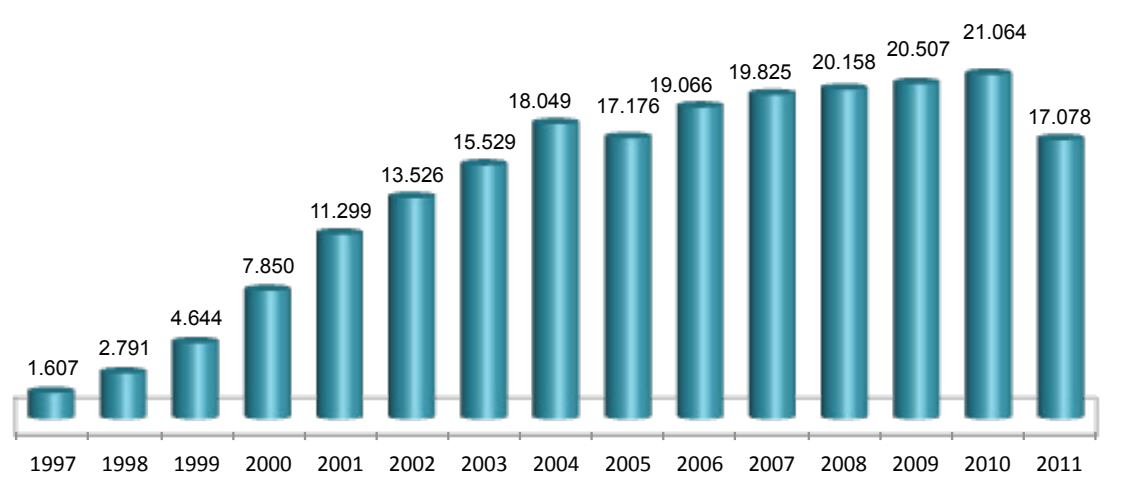

Figura1. Préstamo de libros entre las instituciones del CBUC

uso de un mismo sistema de gestión integrada permitieron a las bibliotecas extender el servicio de préstamo no sólo a la colección propia sino a todas las de las demás bibliotecas. Lo que antes se tenía que pedir por PI a través de un servicio bibliotecario pasó a ser un préstamo más hecho en régimen de autoservicio. Esto ha recibido el nombre de 'préstamo interbibliotecario iniciado por el usuario', 'préstamo remoto' o 'préstamo consorciado'2 2 . Este tipo de préstamo entre bibliotecas se ha popularizado en la última década y en la bibliografía profesional encontraremos no sólo experiencias de los Estados Unidos de América (Chmelir, 2005), sino de Hong Kong (So, 2010) o Finlandia (Muhonen, 2006).

El servicio de préstamo consorciado persigue un mayor uso de las colecciones y un ahorro de costes de personal en el servicio de PI (Munson, 2006, p. 374). Su implantación en consorcios de bibliotecas crea un nuevo universo para el usuario ya que este pasa de tener como colección propia la de la universidad a la que pertenece a tener la totalidad de las colecciones de las bibliotecas miembros del consorcio.

\section{El préstamo interbibliotecario del CBUC y sus limitaciones}

El servicio de préstamo interbibliotecario del $C B \cup C^{3}$ se inició en 1997 (Guallar, 2010, p. 546). Un año antes, con la creación del Catàleg Col·lectiu de les Universitats de Catalunya (CCUC) se vio la necesidad de homogeneizar los servicios de PI de las diferentes universidades integrantes del consorcio. Para ello se creó un grupo de trabajo formado por representantes de las instituciones consorciadas que estudió los requisitos y procedimientos necesarios para llevar a cabo el proyecto.

El fruto de este análisis fue un reglamento aprobado por los directores de las bibliotecas miembros del CBUC de marzo de 1997 que sentó las bases del futuro servicio. Este documento incluía no sólo los principios básicos a seguir, sino que también definía toda la estructura del PI, desde las solicitudes a las tarifas pasando por el circuito de mensajería.

De 1997 a 2004 se hicieron varias modificaciones para adaptar el reglamento a las necesidades que iban surgiendo, así como también para incluir la Universitat Jaume I de Castellón y la Universitat de Vic. El servicio de PI tuvo una buena acogida desde el comienzo, como lo muestran las estadísticas que año tras año van en aumento, y que son analiza- das anualmente por un grupo de trabajo compuesto por un representante de cada institución del CBUC.

Cuando se inició el servicio y durante bastantes años se dio la misma prioridad en servir a una institución consorciada que a otra externa al consorcio. Esto cambió en 2009 cuando se acordó que las peticiones que se recibían de bibliotecas del consorcio y de las demás instituciones colaboradoras del CCUC tenían prioridad respecto a las demás

peticiones.

La figura 1 muestra la evolución de los préstamos interbibliotecarios de libros desde los inicios del PI hasta 2011 y constata los crecimientos mencionados hasta que, este último año, los préstamos disminuyeron notablemente gracias a la puesta en funcionamiento del nuevo servicio de préstamo consorciado que provocó que parte de las peticiones de 2011 no se realizaran ya a través del PI tradicional. Así, además de los 17.078 préstamos vía $\mathrm{PI}$, de octubre a diciembre de 2011 se realizaron 10.821 préstamos a través del nuevo servicio de préstamo que no están incluidos en esta figura.

La figura 1 no incluye tampoco datos sobre las peticiones de fotocopias dado que en este artículo se ha optado por ceñirse al préstamo de documentos originales y no al servicio de fotocopias que normalmente se incluye en el concepto de PI. Pero merece la pena destacar el importante decremento que ha tenido la petición de fotocopias gracias a la contratación consorciada de revistas y libros electrónicos (figura 2).

\section{Se ha popularizado el llamado préstamo interbibliotecario iniciado por el usua- rio, préstamo remoto o préstamo con- sorciado}

A pesar de la eficacia del servicio de PI, el sistema tenía limitaciones. Por un lado no estaba integrado en el software de gestión de bibliotecas sino que funcionaba con un programa independiente (el GTBib-SOD). Así, una vez había encontrado la información a través del CCUC o de los catálogos locales, el usuario tenía que formalizar la petición del documento mediante formularios que requerían la posterior intervención del personal de los servicios, cosa que alargaba los tiempos de recepción de los documentos.

El CCUC tampoco permitía al usuario ver el estado de los ejemplares de cada biblioteca del CBUC, es decir ver si estaban prestados, obligando a consultar el documento en los catálogos locales para conocer si estaba disponible o no. Además, al inicio del servicio de PI las bibliotecas cobraban las peticiones aunque algunas dejaron de hacerlo de forma progresiva. 


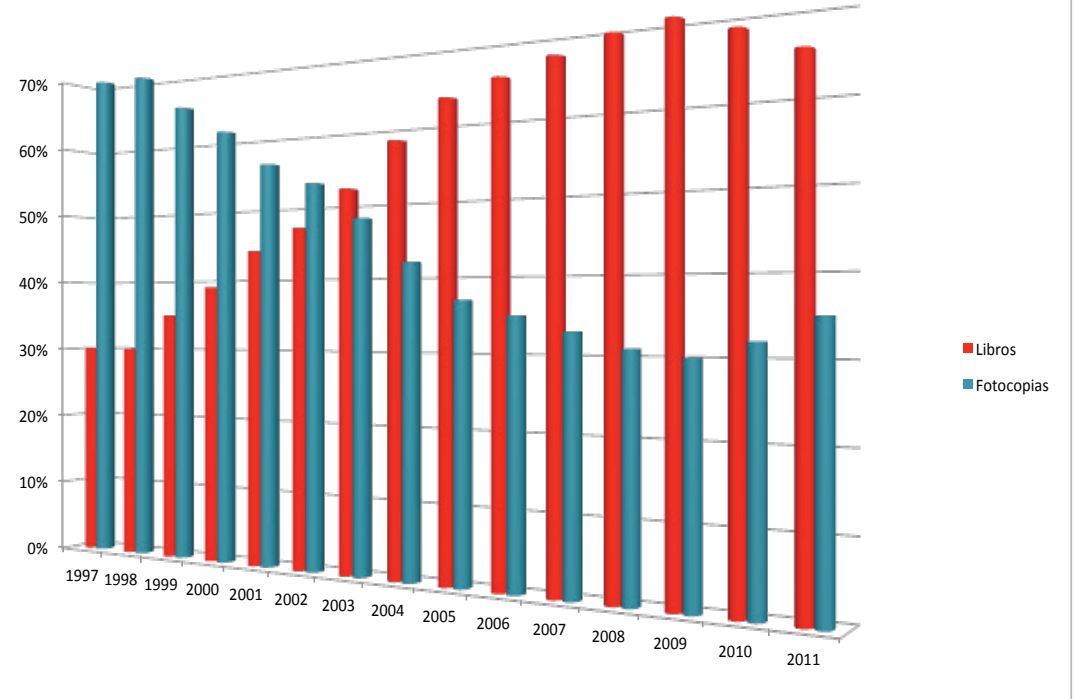

Figura 2. Porcentaje de libros pedidos en préstamo vs fotocopias solicitadas

y su ciclo de vida.

- Sistema de preservación, que abarcaría todos los procedimientos y productos, para gestionar la vida de los documentos digitales (tanto nacidos digitales como escaneados).

- Préstamo interbibliotecario consorciado.

El ERM, el DOMS y la preservación no se han llegado a implementar básicamente porque se ha visto que son productos que han tenido una baja implantación hasta ahora y los productos comerciales son, aún hoy, casi inexistentes.

Los recursos económicos disponibles en aquel momento no permitían dotarse de todos los componentes descritos. Los directores de bibliotecas

\section{El nuevo servicio de préstamo consorciado del CBUC}

En 2005 el CBUC coordinó un concurso público para la selección conjunta de un sistema de gestión bibliotecaria para las redes de bibliotecas municipales (gestionadas por la Diputació de Barcelona y el Departament de Cultura de la Generalitat de Catalunya), las bibliotecas de las universidades públicas de Catalunya y la Biblioteca de Catalunya (Anglada, 2006).

El concurso se dividió en dos lotes, uno para la gestión tradicional de la biblioteca y otro para la gestión de la biblioteca digital. La implementación de los sistemas elegidos (Millennium de la empresa Innovative Interfaces y SFX de Exlibris) se realizó entre 2006 y 2008 . Al final de este proceso, los directores de bibliotecas del $C B \cup C$ examinaron de nuevo el panorama tecnológico para determinar qué necesidades quedaban por cubrir. Así, en 2009 se detectaron los componentes que entonces se consideraron necesarios para una gestión automatizada integral de una biblioteca académica o de investigación (figura 3), que incluye los productos principales suministrados por el concurso (catálogos, repositorios, herramientas de búsqueda, etc.) y los complementarios.

Éstos, tal como fueron definidos entonces, eran:

- Herramienta de descubrimiento (discovery interface) para proporcionar búsquedas bibliográficas más ricas que las de los tradicionales OPACs, enriquecer los registros bibliográficos (con, por ejemplo, imágenes de cubiertas, palabras clave, sugerencias, comentarios, etc.) y permitir búsquedas conjuntas en el catálogo y en el contenido contratado de libros o revistas electrónicas.

- Gestor de recursos electrónicos (ERM, electronic resource management), para gestionar la biblioteca digital de forma similar a como la biblioteca gestiona los documentos en papel.

- Gestor de objetos digitales (DOMS, digital object management system) para crear repositorios digitales y gestionar documentos (ya sea texto, imágenes, etc.), sus metadatos del $C B U C$ analizaron las opciones y productos existentes y lo que hacían otras bibliotecas o consorcios similares al CBUC a nivel internacional. Se decidió no optar por sistemas que parecían no estar tecnológicamente maduros y preferir software que permitiera prestar un servicio directo al usuario. Se llegó a la conclusión que había dos ámbitos de mejora posible y rápida: la presentación al usuario del catálogo (OPAC) y el servicio de préstamo entre las bibliotecas del CBUC.

Por lo que respecta al OPAC, aunque el sistema elegido en el concurso ya presentaba mejoras respecto al anterior, estaban apareciendo entonces en el mercado los llamados OPACs 2.0 que ofrecían mejores posibilidades al usuario (facetas, opción "quiso decir?", incorporación de imágenes, contenido externo, etc.).

Respecto al préstamo consorciado, en el CBUC no estaba automatizado y tampoco había herramientas comerciales, hasta entonces, que se pudieran utilizar directamente para hacerlo. La estrecha relación del servicio de préstamo consorciado con el catálogo conducía a trabajar conjuntamente con la empresa desarrolladora del software de gestión: la empresa Innovative Interfaces y el CBUC acordaron un partenariado para crear un nuevo programa que diera respuesta a la mejora de la visibilidad de los ejemplares en el CCUC y funcionalidades 2.0 y al mismo tiempo fuera una herramienta de gestión del préstamo consorciado del CBUC.

¿Cómo funcionaría este partenariado? En la modalidad early adopter. La empresa desarrolla un programa que el cliente (en este caso el $C B U C$ ) es el primero en probar en las fases más preliminares y, según la respuesta y las diferentes reuniones técnicas que se van teniendo durante el proyecto, se va modelando el producto final.

El préstamo consorciado se definió como un servicio donde los usuarios pudieran iniciar las peticiones de documentos, se liberaran tareas de los servicios de PI y se acortaran los tiempos de recepción de los materiales. Se quería que en vez de un servicio de préstamo "entre bibliotecas" fuera un servicio directo entre el usuario y la biblioteca que tenía el 
documento. Este nuevo sistema debería, además, visualizar los registros del CCUC con la información de los ejemplares locales y su estado. A la vez se quería mejorar y modernizar la consulta al CCUC con una herramienta de descubrimiento.

Con estos requerimientos se aumentaría la velocidad y la eficacia, se reduciría el coste en la petición y obtención de los documentos, se optimizaría el uso de las colecciones gracias a una mayor visibilidad de la información a los usuarios y se reduciría el tiempo de trabajo del personal implicado en el servicio de préstamo y obtención de documentos. Los usuarios dispondrían de una herramienta de descubrimiento aplicada al CCUC con acceso en tiempo real a la información de disponibilidad de los ejemplares de los catálogos locales.

\section{Soluciones: reglamento del PUC y logística del servicio}

Aceptada la opción del partenariado, se creó una Comisión Técnica (CT) que planificó e hizo propuestas de funcionamiento. Propuso un reglamento, el funcionamiento logístico y un calendario de implementación. Se creó también un grupo técnico de trabajo para configurar el sistema, hacer pruebas y reportar a la empresa los errores que se encontraban y sugerir mejoras. Al nuevo servicio de préstamo del CBUC se le llamó PUC (Préstamo de libros entre las bibliotecas del CBUC) y se inauguró el 4 de octubre de 2011.

EI PUC funciona a través de una nueva interfaz de consulta implementada sobre el CCUC:

http://puc.cbuc.cat

Permite, pues, consultar los 10 millones de documentos físicos que se encuentran en las bibliotecas que integran el CCUC y pedir en préstamo aquellos que están disponibles. El CCUC sigue manteniendo, también su OPAC clásico: http://ccuc.cbuc.cat

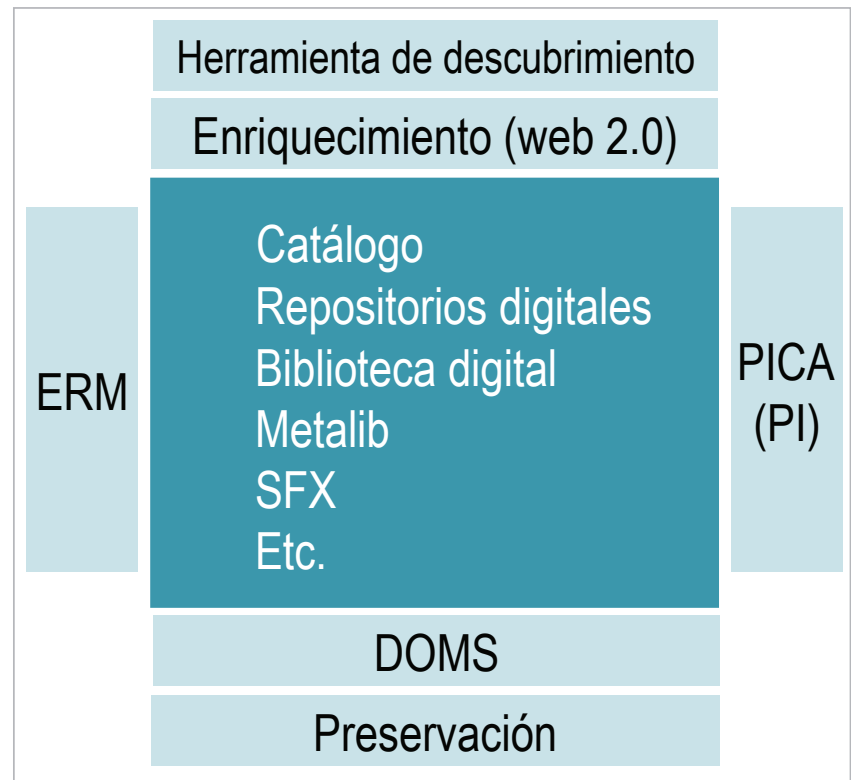

Figura 3. Componentes para una gestión automatizada integral de una biblioteca académica o de investigación
El reglamento del PUC fue acordado por la comisión técnica del CBUC en mayo de 2011 y mejora notablemente los acuerdos anteriores.

El PUC es un servicio gratuito abierto a toda la comunidad universitaria. Las copias de documentos deben continuar solicitándose a través del servicio tradicional de PI de cada institución dado que el PUC es exclusivamente un servicio de préstamo.

\section{EI PUC permite pedir libros directamen- te a la biblioteca que lo posee, sin me- diación del servicio de préstamo}

Se estudió y organizó también toda la logística del nuevo sistema. Básicamente se aprovechó la infraestructura ya utilizada por el servicio tradicional de PI pero ampliando el número de puntos de recogida y el número de maletas físicas del servicio diario de maletas contratado a una empresa privada de mensajería.

Este servicio de mensajería consiste en un servicio fijo de maletas que circulan entre las instituciones del CBUC, cada una de las cuales tiene 2, 3 ó 4 maletas asignadas según el volumen de documentos. La empresa deja y recoge las maletas en los correspondientes puntos de préstamo diariamente.

De acuerdo con la empresa, se ha establecido un protocolo de actuación en caso de pérdida o robo de documentos de las maletas. Este protocolo garantiza la continuidad del servicio de maletas haciendo que se restituyan lo antes posible los documentos que hayan desaparecido y priorizando que el usuario que había solicitado pueda obtenerlos de nuevo en el mínimo tiempo posible. Dentro de las maletas, los libros van siempre en sobres acolchados, debidamente marcados con el lugar de procedencia y de destino.

Desde el inicio del PUC se ha ido evaluando su funcionamiento periódicamente. Si comparamos los datos del primer semestre de 2011 cuando funcionaba sólo el servicio tradicional de PI (17.049 préstamos), con los datos del primer semestre del PUC de 2012 (27.663), vemos que el servicio de préstamo entre las bibliotecas del $C B U C$ ha aumentado un $62 \%$. Además de estos préstamos se han realizado 24.409 renovaciones, función que en el anterior sistema no existía porque en general no había plazos de retorno.

\section{Funcionamiento técnico del PUC}

La empresa Innovative desarrolló para el partenariado con el CBUC el programa llamado Encore for a Group, basado en la combinación y adaptación de dos programas ya existentes. El primero es INN-Reach, que es un software específico para la gestión de catálogos colectivos y préstamo consorciado que permite a las bibliotecas participantes contribuir con sus registros locales a una base de datos central. En el caso presentado aquí, el programa se abastece de los registros bibliográficos del CCUC y de los registros de los 9 catálogos locales del CBUC. Crea un registro máster con la 


\begin{tabular}{|c|c|c|c|c|}
\hline Tipo de usuario & $\begin{array}{c}\text { N. de } \\
\text { documentos }\end{array}$ & $\begin{array}{c}\text { N. de } \\
\text { renovaciones }\end{array}$ & $\begin{array}{l}\text { Días documento } \\
\text { impreso }\end{array}$ & $\begin{array}{l}\text { Días documento } \\
\text { audiovisual }\end{array}$ \\
\hline 1. Estudiantes de grado, $1 \mathrm{r}$ y $2^{\circ}$ ciclo & 4 & 4 & 10 & 5 \\
\hline 2. Estudiantes de postgrado, $3 \mathrm{r}$ ciclo, masters y doctorandos & 8 & 4 & 20 & 5 \\
\hline $\begin{array}{l}\text { 3. Personal docente e investigador de las universidades y } \\
\text { usuarios de la Biblioteca de Catalunya }\end{array}$ & 8 & 4 & 20 & 5 \\
\hline $\begin{array}{l}\text { 4. Personal de administración y servicios de las } \\
\text { universidades y trabajadores de la Biblioteca de Catalunya }\end{array}$ & 8 & 4 & 20 & 5 \\
\hline 5. Otros usuarios autorizados & 4 & 4 & 10 & 5 \\
\hline
\end{tabular}

Tabla 1. Cuadro resumen de los tipos de usuario y número máximo de documentos, renovaciones y días de renovación de los préstamos

información del registro del CCUC (que es el que visualiza el usuario) y añade la información de los ejemplares físicos de cada una de las instituciones que también tienen este registro. El segundo programa, Encore, es una potente herramienta de descubrimiento que da una mejor experiencia de búsqueda a los usuarios. Ambos programas funcionan en servidores independientes hospedados en las instalaciones de Innovative.

Para la fusión de todos los registros se utiliza la coincidencia del valor de la etiqueta 001 del formato MARC21, cuyo uso en el CCUC empezó con la migración al programa Millennium. Se trata de tener un número único identificador de cada registro que esté en todos los catálogos del CCUC que tienen el mismo registro. En los registros de nueva creación este número se copia automáticamente al catálogo local, pero en los registros creados anteriormente a la migración se ha hecho un importante trabajo semi-automatizado de búsqueda y creación de esta etiqueta en todos los catálogos.

Las herramientas de descubrimiento, como Encore de Innovative, presentan resultados facetados, nubes de etiquetas, ¿querías decir?, sugerencias, ranking de relevancia...

Durante la fase de implementación una persona de cada institución fue la encargada de configurar su sistema local, y desde la oficina del $C B \cup C$ se realizó la configuración del servidor central. Estas personas también fueron las encargadas de hacer las primeras pruebas y comprobaciones antes de iniciar la prueba piloto. En cada catálogo local se introdujeron las nuevas reglas de préstamo, los nuevos tipos de usuarios, los ejemplares PUC y las nuevas tablas de bloqueos. No se tuvieron que modificar las reglas de préstamo local.

En el sistema central se configuraron unas tablas de equivalencias de ejemplares y de usuarios, específicas para cada institución, que sirven para asignar un código de ejemplar y de usuario PUC común a todas las instituciones, y aplicar las reglas de préstamo sin afectar a las reglas del préstamo local. La gestión de los préstamos PUC por parte del personal de la biblioteca se hace con el mismo programa usado para los préstamos locales, comunicándose con el servidor central mediante un protocolo de comunicación propio de la empresa Innovative.

\section{Usuarios}

El PUC pueden usarlo todos los usuarios de las instituciones consorciadas a los que se les ha dado permiso. El sistema, que no tiene una base de datos de usuarios propia, antes de realizar una transacción de préstamo comprueba si el usuario existe en alguna institución, si tiene permiso de utilización del servicio y si no tiene faltas, bloqueos ni devoluciones pendientes.

El sistema envía las comunicaciones de los préstamos a los usuarios desde la institución a la que pertenece, por lo que los mensajes tienen la misma personalización y estilo que cualquier otro de la institución. Este método de trabajo permite a cada institución tener el control total sobre sus usuarios y poder gestionarlos a su manera.

\section{Estadísticas}

Es posible extraer datos estadísticos desde el propio sistema central y también desde el sistema de estadísticas de cada institución. Las centrales se refieren a las reservas, cancelaciones y préstamos, y las locales a renovaciones y bloqueos. Cada institución puede saber qué uso hacen sus usuarios de este servicio y también qué porcentaje de su colección está siendo utilizado.

\section{Interfaz de búsqueda}

El usuario accede a través de la herramienta de descubrimiento Encore de Innovative, que permite hacer la búsqueda sobre todos los registros del PUC y refinarla por diferentes facetas (formato, idioma, etc.). Como se observa en la figura 5, de cada documento muestra información en tiempo real de todos los ejemplares, de los lugares donde se encuentran y de su estado (disponible, hasta qué día está prestado, sólo uso local).

Las peticiones de préstamo PUC se pueden realizar por dos vías:

- por la web del PUC;

- por la biblioteca donde se encuentra el documento, recogiéndolo presencialmente (préstamo in situ).

En ambos casos el usuario puede devolver el documento a cualquiera de las bibliotecas de su institución o a cualquiera de las bibliotecas de la institución a la que pertenece el documento. 


\section{Procedimiento de préstamo}

El usuario entra en la interfaz del sistema PUC en: http://puc.cbuc.cat

Cuando encuentra el documento deseado hace la petición indicando a qué institución pertenece y en qué biblioteca de su institución quiere recogerlo. En ese momento el sistema comprueba si el documento está disponible para a ser prestado y que no pertenezca a la institución del usuario, pide a éste una identificación y comprueba en el catálogo local que tiene acceso al servicio, sin bloqueos ni faltas. Después, el sistema genera la petición del documento en el catálogo propietario.

El personal de la institución propietaria del documento recibe la petición, prepara el documento para ser enviado e informa al sistema que ya ha sido enviado.

Cuando la institución del usuario recibe el documento a través del servicio de mensajería, informa de su recepción al sistema y coloca el documento en los estantes de documentos pendientes de ser recogidos. El sistema genera automáticamente un mensaje al usuario y le informa de que dispone de 4 días para recoger el documento.

Una vez el usuario ha recogido el documento, el sistema guarda el préstamo realizado y lo trata como todos los demás préstamos locales aplicándole los avisos y reclamaciones configuradas que correspondan. Cuando el usuario devuelve el documento, el sistema informa al bibliotecario a qué institución pertenece y éste lo prepara para su devolución por el servicio de mensajería. Cuando la institución propietaria del documento lo recibe, informa al sistema, se borra el préstamo al usuario y se devuelve el documento al estado original. En ningún momento el personal implicado en el préstamo ha tenido que salir de su sistema Millennium local para trabajar y controlar los préstamos PUC.

\section{Situación actual y consideraciones finales}

Las claves de éxito de este proyecto, como en la mayoría de proyectos del $C B \cup C$, han sido la planificación, el liderazgo, el apoyo técnico, la cooperación y la comunicación. La implementación del PUC era compleja ya que requería la participación a diferentes niveles de personas de varias instituciones y-como en otros proyectos consorciados- requería que los participantes compartieran los objetivos y los intereses, hubiera consenso en cómo alcanzarlos, acordaran políticas comunes y fueran flexibles, manteniendo siempre el sentido de cooperación. Poder contar con un sistema automatizado que permitiera el funcionamiento de este nuevo servicio, como es el sistema Millennium y su Encore for a Group, ha sido, también evidentemente imprescindible.

En el poco tiempo de funcionamiento del PUC ya ha alcanzado los objetivos de mejora previstos originalmente. Pero ha habido también varios beneficios no previstos como han sido la nueva formulación y estandarización de algunas políticas de préstamo internas que ha tenido que implementar cada institución. Los grupos de trabajo han sido clave gracias a la creatividad mostrada, la paciencia, la disposición al cambio, la flexibilidad y la asunción de riesgos.

El préstamo consorciado es un claro ejemplo de servicio

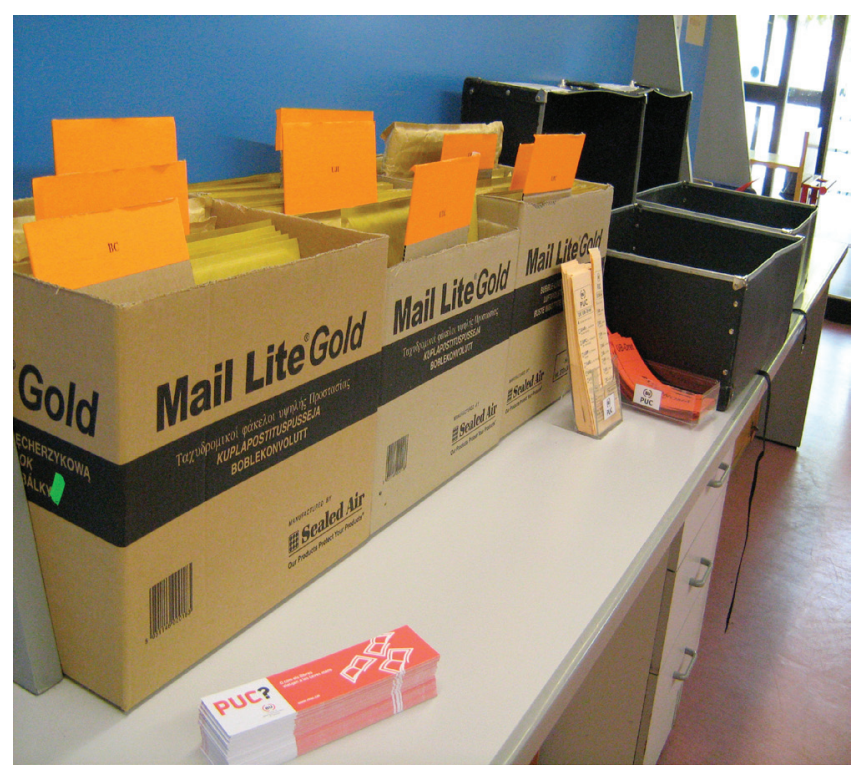

Figura 4. Las maletas del PUC en uno de los puntos de préstamo de la Universitat de Barcelona

"cola larga", tal como ha sido descrito por Anderson (2007). Éste señala que en una distribución estadística convencional la suma de las ocurrencias con bajos usos es una cantidad relevante. El colectivo Laboratorio de Ideas Sobre el Libro afirma:

"Cada vez se venden menos cantidades de libros pero de un mayor número de títulos (...). Así pues, parece claro que el mercado del libro necesita adoptar estrategias alternativas al mercado de masas y abordar planteamientos propios de los modelos de economías de nicho (long tail)".

Un estudio reciente de OCLC muestra que aún acumulando en un sistema cooperativo los libros de bajo uso de muchas instituciones, estos no siempre cubren las necesidades de los usuarios de una sola institución (Malpas, 2011). Dicho de otra forma, el efecto mencionado de cola larga se manifiesta incluso cuando el volúmen de libros a los que se tiene acceso es muy grande.

Los servicios de PI y los de PI mejorado como es el caso del préstamo consorciado permiten no sólo acceder a libros incorporados a la colección 'just-in-case' sino también a los que satisfacen necesidades informativas minoritarias y especializadas que se encuentran en otras bibliotecas. Es decir, por buenos que sean los servicios de selección bibliográfica de una biblioteca universitaria y por cuantiosos que sean los recursos dedicados a adquisiciones, los usuarios necesitarán libros que no forman parte de nuestras colecciones. A través de servicios cooperativos como los catálogos colectivos y el préstamo consorciado, las bibliotecas pueden aumentar su capacidad de atender más peticiones.

\section{Notas}

1. La última revisión consultada ha sido la de McGrath, Mike (2012), octubre, v. 40, n. 4 [pre-print].

2. Algunos autores consideran que el préstamo consorciado es una forma de préstamo, no un préstamo interbibliotecario (v. Kohl, David, 1998, pp. 65-69). 
Buscar en el PUC: biblioteca digital semantica

Hacia la biblioteca digital semántica / José Manuel Morales del Castillo
Morales del Castillo, José Manuel, 1974-
Somonte-Cenero, Gijón : Trea, cop. 2011

Figura 5. Registro PUC mostrando la disponibilidad de los ejemplares en tiempo real

3. Los miembros del CBUC son las universidades de Barcelona, Autònoma de Barcelona, Politècnica de Catalunya, Pompeu Fabra, Girona, Lleida, Rovira i Virgili, Oberta de Catalunya, y la Biblioteca de Catalunya.

\section{Bibliografía}

Anderson, Chris. La economía long tail: de los mercados de masas al triunfo de lo minoritario. Barcelona: Urano, 2007. ISBN: 9788493464264

Anglada, Lluís M. "Veinticinco años de automatización de bibliotecas en Cataluña". BiD: textos universitaris de biblioteconomia i documentació, 2006, juny, n. 16. http://www.ub.edu/bid/16angla2.htm

Chmelir, Lynn. "Patron-initiated borrowing and traditional ILL: the cascade experience". Interlending \& document supply, 2005, v. 33, n. 1, pp. 35-41.

http://dx.doi.org/10.1108/02641610510582126

Guallar, Javier. "Reflexiones sobre bibliotecas. Entrevista a Lluís Anglada". El profesional de la información, 2010, sept.oct., v. 19, n. 5, pp. 545-551.

http://dx.doi.org/10.3145/epi.2010.sep.16

Kohl, David. "How the virtual library transforms interlibrary loans - the OhioLINK experience". Interlending \& document supply, 1998, v. 26, n. 2, pp. 65-69.

http://dx.doi.org/10.1108/02641619810213718

Laboratorio de Ideas sobre el Libro. "La gran transformación: Panorama del sector del libro en España 2012-2015". Madrid, 2012. http://laboratoriodellibro.com/project/la-gran-transformacion

Mak, Collette. "Resource sharing among ARL libraries in the US: 35 years of growth". Interlending \& document supply, 2011, v. 39, n. 1, pp. 26-31.

http://dx.doi.org/10.1108/02641611111112110

McGrath, Mike. "Interlending and document supply: a review of the recent literature: 80". Interlending \& document supply, 2012, octubre, v. 40, n. 4 [pre-print].

Malpas, Constance. Cloud-sourcing research collections: managing print in the mass-digitized library environment. Dublin (Ohio): OCLC Research, 2011.

http://www.oc/c.org/research/publications/ library/2011/2011-01.pdf

Muhonen, Ari; Jauhiainen, Annu; Vattulainen, Pentti. "Sharing resources in Finnish university libraries: reorganising the national document supply system". Interlending \& document supply, 2006, v. 34, n. 2, pp. 51-56.

http://dx.doi.org/10.1108/02641610610669732

Munson, Doris M. "Comparison of Summit Union Catalog borrowing and interlibrary loan returnables at Eastern Washington University". Journal of library administration, 2006, v. 45, n. 3-4, pp. 361-376.

http://dx.doi.org/10.1300/J111v45n03_03

So, Edwuard; Ho, Winnie. "Inter-library access solution in Hong Kong academic libraries". Interlending \& document supply, 2010, v. 38, n. 4, pp. 237-244.

http://dx.doi.org/10.1108/02641611011094383 